\title{
Toxicological study of Zaleplon (Anxiolytic drug) in experimental animals.
}

\author{
Mostafa E. El-Naggar ${ }^{1}$, Hassan M. El-Fayoumi ${ }^{2}$, Nabila N. El-Maraghy ${ }^{2}$, Wafaa I. \\ El-Eraky ${ }^{3}$ and Siham M. El-Shenawy ${ }^{3}$ \\ ${ }^{1}$ Department of narcotics, ercogenics and poisons, National research center, Egypt \\ ${ }^{2}$ Department of pharmacology, Faculty of pharmacy, Zagazig University, Egypt \\ ${ }^{3}$ Department of pharmacology, National research center, Egypt
}

\section{ABSTRACT}

Anxiety disorders are among the most prevalent mental disorders in the general population. Nearly 30 million persons are affected in the United States, with women affected nearly twice as frequently as men. These disorders are frequently treated using benzodiazepines (Diazepam) and non-benzodiazepines (Zaleplon). Non-benzodiazepines have replaced the benzodiazepines for anxiety treatment due to low risk of dependence and CNS effects encouraging drug abuse.

This work was designed to investigate the toxicological overdose effect of zaleplon and diazepam on behavior, blood pressure, heart rate, brain neurotransmitter content and liver \& kidney functions in rats.

Rats were divided into five groups: $1 \%$ Tween 80 , p.o. (control), diazepam ( $1 \& 4$ $\mathrm{mg} / \mathrm{kg}$, p.o.) and zaleplon (1 \& $4 \mathrm{mg} / \mathrm{kg}$, p.o.). All groups were injected daily for four weeks to perform the following: behavioral study (assessment of motor co-ordination and anxiety performance), measurement of blood pressure $\&$ heart rate, determination of the free amino acid and monoamine contents in the whole brain, determination of serum aminotransferases activity, total protein, total and direct billirubin, creatinine \& blood urea nitrogen of experimental rats.

Zaleplon decreased motor co-ordination, blood pressure and heart rate with extent lesser than diazepam. However, it decreased anxiety performance and brain monoamine content with extent more than diazepam. While, diazepam increased brain amino acid content, serum aminotransferases activity, total protein, total \& direct billirubin, creatinine and blood urea nitrogen by magnitude more than zaleplon.

These results suggest that: zaleplon is safer than diazepam in treatment of anxiety. Keywords: Diazepam, zaleplon, anxiolytic, motor co-ordination \& anxiety performance.

\section{INTRODUCTION}

Anxiety is a psychological and physiological state characterized by somatic, emotional, cognitive and behavioral components. It is the displeasing feeling of fear \& concern, worry, uneasiness and dread. It may help an individual to deal with a stressor by prompting them to cope with it (Henig, 2009). It may include heart palpitations, tachycardia, muscle weakness \& tension, fatigue, nausea, chest pain, shortness of breath, headache, stomach aches or tension headaches. As the body prepares to deal with a threat; blood pressure, heart rate, perspiration and blood flow to the major muscle groups are increased, while immune and digestive functions are inhibited. External signs of anxiety may include; pallor, sweating, trembling and pupillary dilatation (Davison and Gerald, 2008; Carlson and Donald, 2010).

When anxiety becomes excessive, it may fall under the classification of an anxiety disorders. These disorders have been widely reported throughout the world commonly in older adults. Where, anxiety is a subjective perception of dissatisfaction with the amount and/or 
quality of sleep or early awakening with inability to fall asleep again (Sylvers et al., 2011).

Anxiety disorders are among the most prevalent mental disorders in the general population. Nearly 30 million persons are affected in the United States, with women affected nearly twice as frequently as men. These disorders are associated with significant morbidity and often are chronic and resistant to treatment (Curran and Chalasani, 2012) and they can be viewed as a family of related but distinct mental disorders, which include the following: panic disorder with or without agoraphobia, agoraphobia with or without panic disorder, specific phobia, social phobia, obsessive-compulsive disorder (OCD), post-traumatic stress disorder (PTSD), acute stress disorder and generalized anxiety disorder (Doyle and Pollack, 2003; Pigott, 2003; Henig, 2009).

Sleep disorders are frequently treated using benzodiazepine (ex. Diazepam) and non-benzodiazepine (ex. Zaleplon) anxiolytics (Morin et al., 2004; Dolder et al., 2007). Where, anxiolytics should be prescribed for short periods only with the frequency and duration of use customized to each patient's circumstances (Ramakrishnan and Scheid, 2007).

Benzodiazepine anxiolytics are most useful for short term treatment in promoting sleep. However, long term use may lead to adverse effects and withdrawal phenomena, such as; sleepiness and reduced alertness (Becker, 2006; Naghibi and Rayatnia, 2011). In contrast, the newer generation non-benzodiazepine anxiolytics have no significant adverse effects and withdrawal phenomena when taken as recommended, making them the best first line choice for long term treatment of anxiety (Follesa et al., 2002; PandiPerumal et al., 2006). Also, the nonbenzodiazepines have largely replaced the benzodiazepines for anxiety treatment due to low risk of tolerance, dependence and residual central nervous system effects compared with benzodiazepine anxiolytics (Noguchi et al., 2002; Ganzberg et al., 2005; Foda and Bakhaidar, 2010). So, these benefits of non-benzodiazepine anxiolytics encourage the patients to take overdose of this type of anxiolytics leading to drug abuse.

The aim of this work was to investigate the toxicological overdose effect of some anxiolytic drugs (ex. Zaleplon and Diazepam) on behavior, blood pressure, heart rate, brain neurotransmitter content and liver \& kidney functions in experimental animals by using several parameters as well as to study the probable mechanism(s) of action of these anxiolytic drugs.

\section{MATERIALS AND METHODS Animals}

Male Sprague Dawley rats (120 $130 \mathrm{gm})$ were purchased from the animal house of National research center (Dokki, Giza, Egypt). Animals were acclimatized in the animal house of pharmacology department - National research center of Egypt, for at least one week prior to experimentation. Animals were kept at $22 \pm 3^{\circ} \mathrm{c}$ and $5 \%$ relative humidity during the whole experiment. Standard food pellets and water were supplied. Animals' treatment protocol was approved by National Research Center Animal Right Committee.

\section{Drugs}

In the current study, diazepam and zaleplon were used and obtained from Egyptian International Pharmaceutical Industries Co. (EIPICO), Egypt, and 
Sigma company, Egypt, respectively. These drugs were suspended in sterile bidistilled water using $1 \%$ tween 80 immediately before administration.

\section{Experimental design}

Animals (Adult male Sprague Dawley rats) were randomly divided into five groups; each consists of ten animals according to the following scheme:

Group (1): 1\% Tween 80, p.o. and served as control. p.o.).

Group (2): Diazepam (1 mg/kg, p.o.).

Group (3): Diazepam (4 mg/kg,

$$
\begin{aligned}
& \text { Group (4): Zaleplon (1 } \mathrm{mg} / \mathrm{kg} \text {, } \\
& \text { p.o.). } \\
& \text { proup (5): Zaleplon (4 } \mathrm{mg} / \mathrm{kg} \text {, }
\end{aligned}
$$

All groups were administered daily for four successive weeks.

Biochemical measurement

Blood samples were obtained from retro-orbital plexus of veins of each animal under light anaesthesia by diethyl ether, 24 hours after last treatment, and collected in non-heparinized tubes. The non-heparinized blood was allowed to coagulate and then centrifuged to separate the serum. Serum was obtained by blood centrifugation at $2500 \mathrm{rpm}$ for 10 minutes, liquated and stored at $-20^{\circ} \mathrm{C}$ for biochemical analysis (Cocchetto and Bjornsson, 1983).

\section{METHODS}

The present study was done by the following: a) Behavioral study including assessment of motor co-ordination by using the rotarod test (Kauppila et al., 1991; Lundblad et al., 2003) and anxiety performance by using the elevated plus maze test (Salum et al., 2003; Braun et al., 2011). b) Measurement of blood pressure and heart rate by using tail-cuff technique (Irvine et al., 1997). c) Determination of the free amino acid and monoamine contents in the whole brain by using HPLC (Heinrikson and Meredith, 1984; Pagel et al., 2000). d) Determination of serum aminotransferases activity (Reitman and Frankel, 1957), total protein (Henry et al., 1974), total \& direct billirubin (Walter and Stucki, 1970), creatinine (Degiorgio, 1974) and blood urea nitrogen (Tabacco et al., 1979).

\section{Statistical analysis}

Data were presented as mean \pm Standard error. Comparisons between means were carried out using two way ANOVA test. When a significant $F$ value was obtained, Bonferroni post hoc analysis was performed to determine specific differences.

A probability level of less than 0.05 was accepted as being significant in all types of statistical tests. SPSS software program (version 14) was used to carry out all statistical tests.

\section{Behavioral study}

\section{RESULTS}

\section{Effect of diazepam and zaleplon on rats' motor co-ordination}

Diazepam (1 $\mathrm{mg} / \mathrm{kg}$, p.o.) and zaleplon (4 $\mathrm{mg} / \mathrm{kg}$, p.o.) decreased rotarod performance significantly by $16.5 \%$ and $17.5 \%$ after four weeks respectively, while diazepam $(4 \mathrm{mg} / \mathrm{kg}$, p.o.) decreased rotarod performance significantly by $18.7 \%$ after 30 minutes, $19.2 \%$ after two weeks and $21.8 \%$ after four weeks as compared with corresponding control group values as shown in Figure (1).

\section{Effect of diazepam and zaleplon on} rats' anxiety performance

Diazepam (1 and $4 \mathrm{mg} / \mathrm{kg}$, p.o.) showed significant increase in anxiety performance by $52.2 \% \& 99.3 \%$ after 30 minutes, $61.6 \% \& 107.4 \%$ after two weeks and $109.7 \%$ \& $140.7 \%$ after four weeks respectively. In addition, for 
zaleplon (1 and $4 \mathrm{mg} / \mathrm{kg}$, p.o), anxiety performance was increased significantly by $85.5 \% \& 105.7 \%$ after 30 minutes, $58.7 \%$ \& $103.7 \%$ after two weeks and
$53.8 \% \quad \& \quad 86.7 \%$ after four weeks respectively comparing to corresponding control group values as shown in Figure (2).

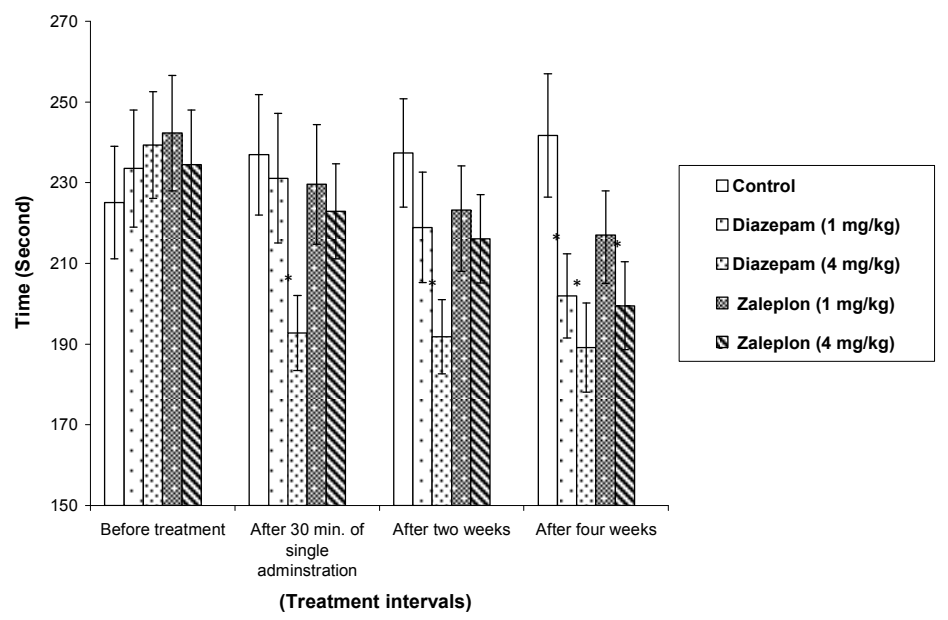

Figure 1. Effect of diazepam and zaleplon on rats' motor co-ordination.

* Significantly different from corresponding control group values at $(\mathrm{p}<0.05)$.

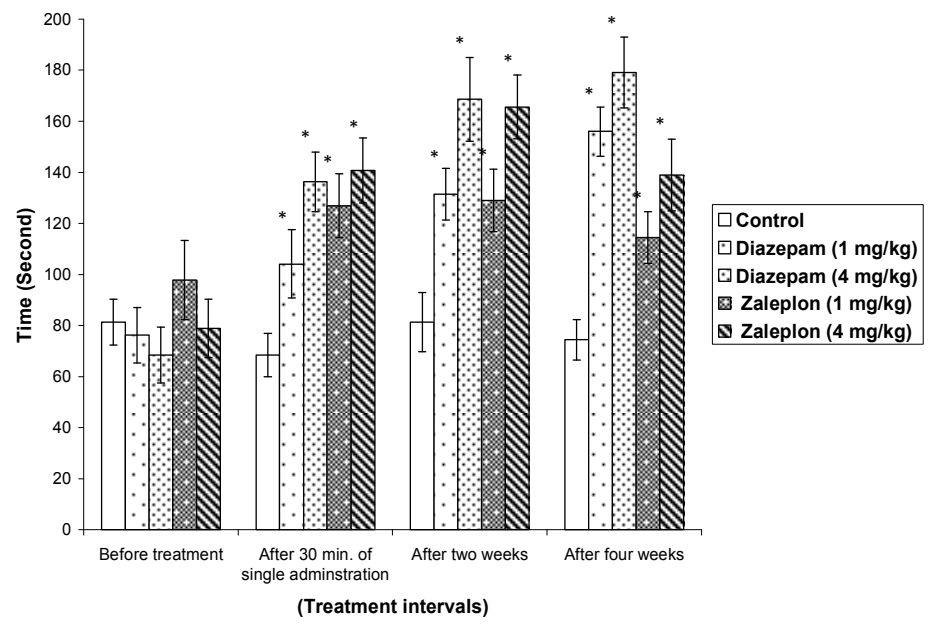

Figure 2. Effect of diazepam and zaleplon on rats' anxiety performance.

* Significantly different from corresponding control group values at $(\mathrm{p}<0.05)$.

Effect of diazepam and zaleplon on rats' blood pressure

Diazepam (1 $\mathrm{mg} / \mathrm{kg}$, p.o.) and zaleplon (4 mg/kg, p.o.) caused significant decrease on blood pressure by $13.8 \%$ and $15.4 \%$ after four weeks respectively. While, diazepam $(4 \mathrm{mg} / \mathrm{kg}$, p.o.) caused significant decrease on blood pressure by $15.6 \%$ after 30 minutes, $11.7 \%$ after two weeks and $23 \%$ after four weeks in comparison with that of corresponding control group values as shown in Figure (3).

Effect of diazepam and zaleplon on rats' heart rate

Diazepam (1 $\mathrm{mg} / \mathrm{kg}$, p.o.) and zaleplon (4 $\mathrm{mg} / \mathrm{kg}$, p.o.) caused significant decrease on heart rate by 
$6.3 \%$ and $7.5 \%$ after four weeks respectively. While, diazepam $(4 \mathrm{mg} / \mathrm{kg}$, p.o.) caused significant decrease on blood pressure by $8.2 \%$ after 30 minutes,
$8.7 \%$ after two weeks and $11.7 \%$ after four weeks comparing to corresponding control group values as shown in Figure (4).

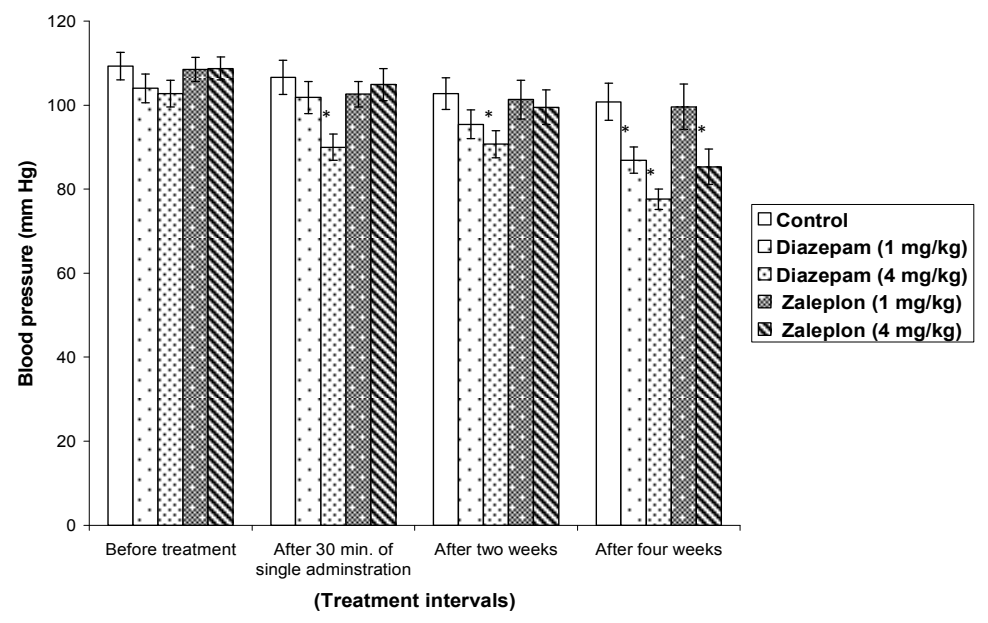

Figure 3. Effect of diazepam and zaleplon on rats' blood pressure.

* Significantly different from corresponding control group values at $(\mathrm{p}<0.05)$.

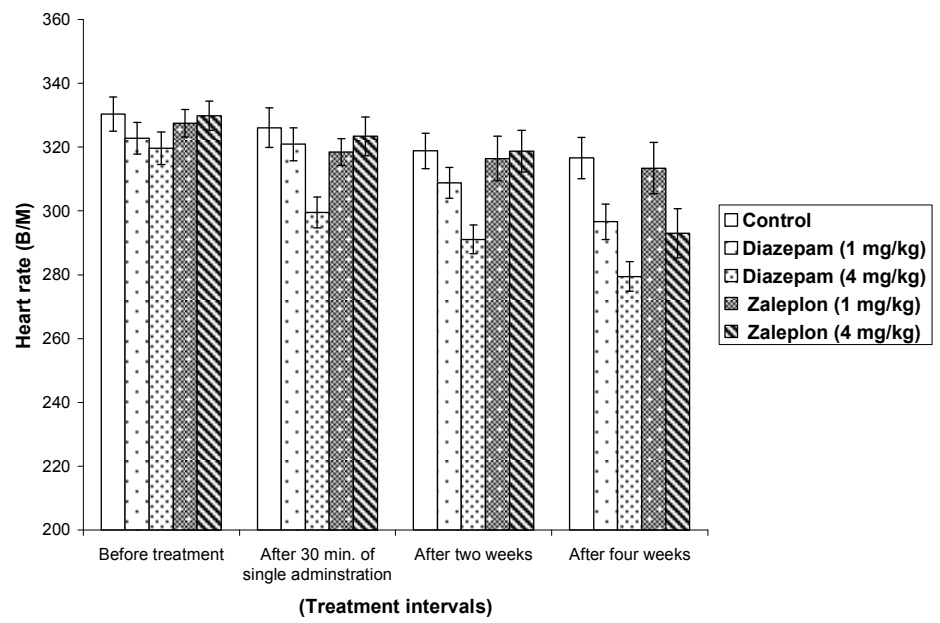

Figure 4. Effect of diazepam and zaleplon on rats' heart rate.

* Significantly different from corresponding control group values at $(p<0.05)$.

Effect of diazepam and zaleplon on rats' free amino acid contents in the whole brain

Diazepam (1 mg/kg, p.o.) caused significant decrease on aspartic acid by $18.2 \%$ and significant increase on GABA by $18 \%$. While, diazepam (4 $\mathrm{mg} / \mathrm{kg}$, p.o.) induced significant decrease on aspartic and glutamic acids by $20 \%$ and $20.9 \%$ respectively, however it caused significant increase on GABA by $26.4 \%$. But for zaleplon (4 mg/kg, p.o.); GABA was increased significantly by $18.2 \%$ as compared with corresponding control group values (Figure 5).

Effect of diazepam and zaleplon on rats' monoamine contents in the whole brain

Diazepam (1 mg/kg, p.o.) caused significant increase on dopamine and 
serotonin by $32 \%$ and $28 \%$ respectively. While, diazepam (4 mg/kg, p.o.) induced significant decrease on nor-epinephrine by $22.8 \%$, significant increase on dopamine and serotonin by $54 \%$ and
$50 \%$ respectively. However for zaleplon (4 $\mathrm{mg} / \mathrm{kg}$, p.o.); serotonin was raised significantly by $30 \%$ in comparison with that of corresponding control group values as shown in Figure (6).

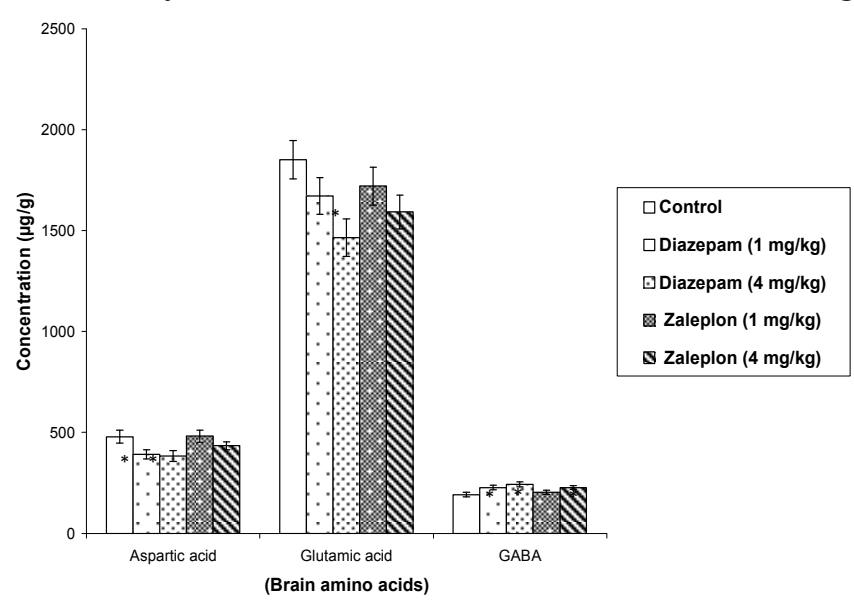

Figure 5. Effect of diazepam and zaleplon on rats' free amino acid contents in the whole brain.

* Significantly different from corresponding control group values at $(\mathrm{p}<0.05)$.

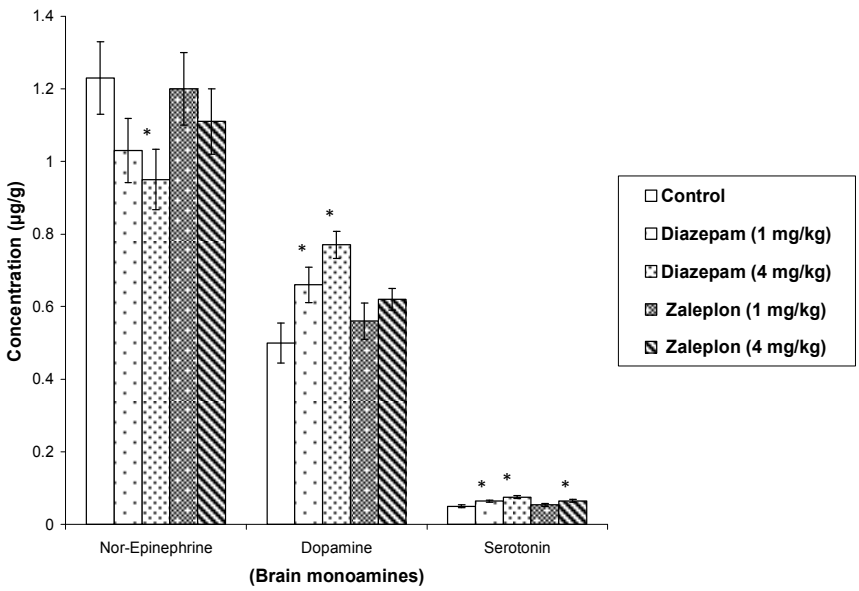

Figure 6. Effect of diazepam and zaleplon on rats' monoamine contents in the whole brain.

* Significantly different from corresponding control group values at $(\mathrm{p}<0.05)$.

\section{Biochemical measurement}

Effect of diazepam and zaleplon on rats' serum aspartate aminotransferase activity

Diazepam (1 mg/kg, p .o.) and zaleplon (1 $\mathrm{mg} / \mathrm{kg}$, p.o.) induced significant increase on AST activity by $24.9 \%$ and $30 \%$ after four weeks respectively.
While, diazepam (4 mg/kg, p.o.) and zaleplon (4 mg/kg, p.o.) caused significant increase on AST activity by $43.4 \% \& 38 \%$ after two weeks and $46.2 \%$ \& $28.6 \%$ after four weeks respectively as compared with corresponding control group values as shown in Figure (7). 
Effect of diazepam and zaleplon on rats' serum alanine aminotransferase activity

Diazepam (1 mg/kg, p.o.) induced significant increase on ALT activity by $45.4 \%$ after four weeks. However, diazepam (4 mg/kg, p.o.) and zaleplon (4 $\mathrm{mg} / \mathrm{kg}$, p.o.) caused significant increase on ALT activity by $68.5 \% \& 30.8 \%$ after two weeks and $87.7 \%$ \& $41.1 \%$ after four weeks respectively comparing to corresponding control group values as shown in Figure (8).

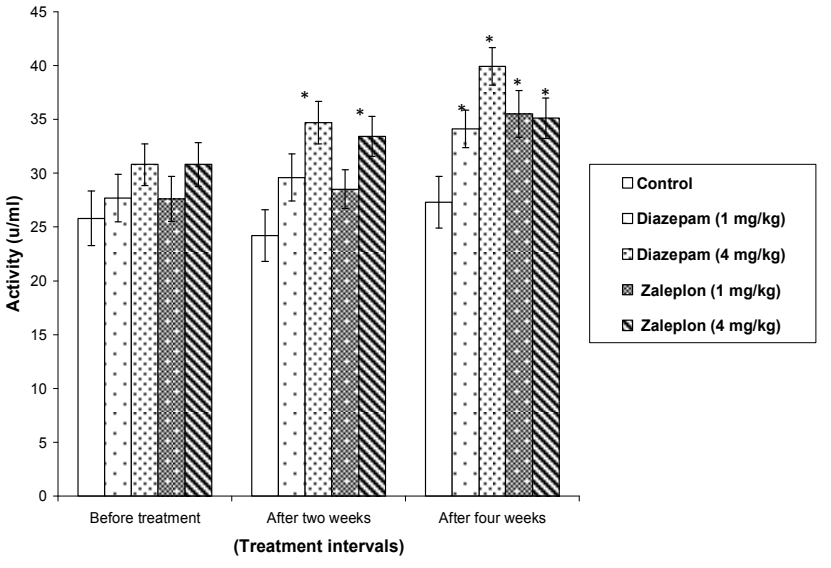

Figure 7. Effect of diazepam and zaleplon on rats' serum aspartate aminotransferase activity.

* Significantly different from corresponding control group values at $(\mathrm{p}<0.05)$.

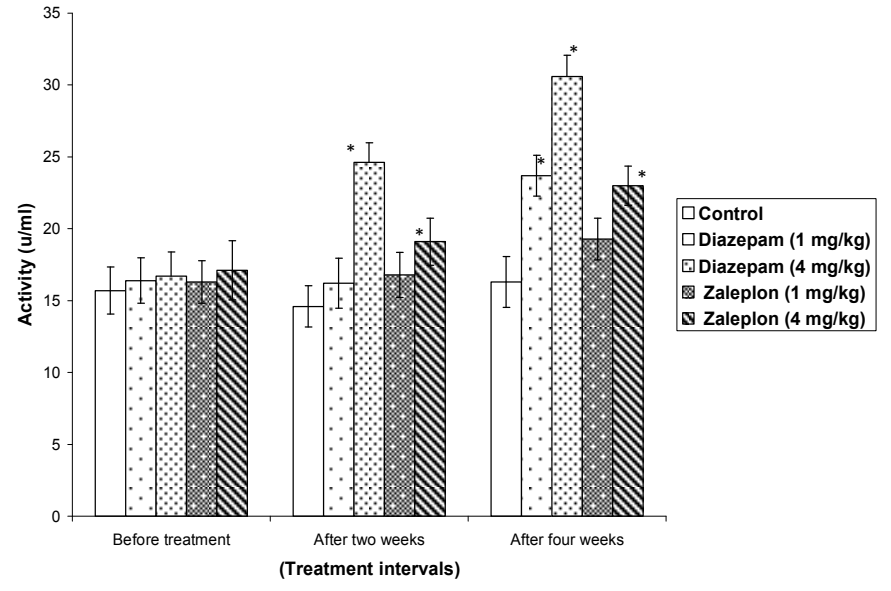

Figure 8. Effect of diazepam and zaleplon on rats' serum alanine aminotransferase activity.

* Significantly different from corresponding control group values at $(\mathrm{p}<0.05)$.

Effect of diazepam and zaleplon on rats' serum total protein

Diazepam (1 and $4 \mathrm{mg} / \mathrm{kg}$, p.o.) and zaleplon (4 mg/kg, p.o.) caused significant decrease on serum total protein by $8.3 \%, 10.5 \%$ and $6.3 \%$ after four weeks respectively comparing to corresponding control group values as shown in Figure (9).

Effect of diazepam and zaleplon on rats' serum direct billirubin

Diazepam (4 $\mathrm{mg} / \mathrm{kg}$, p.o.) showed significant increase on serum direct billirubin by $25 \%$ after two weeks and 
$52.9 \%$ after four weeks. In addition, zaleplon (4 mg/kg, p.o) led to significant increase on serum direct billirubin by
$17.7 \%$ after four weeks as compared with corresponding control group values as shown in Figure (10).

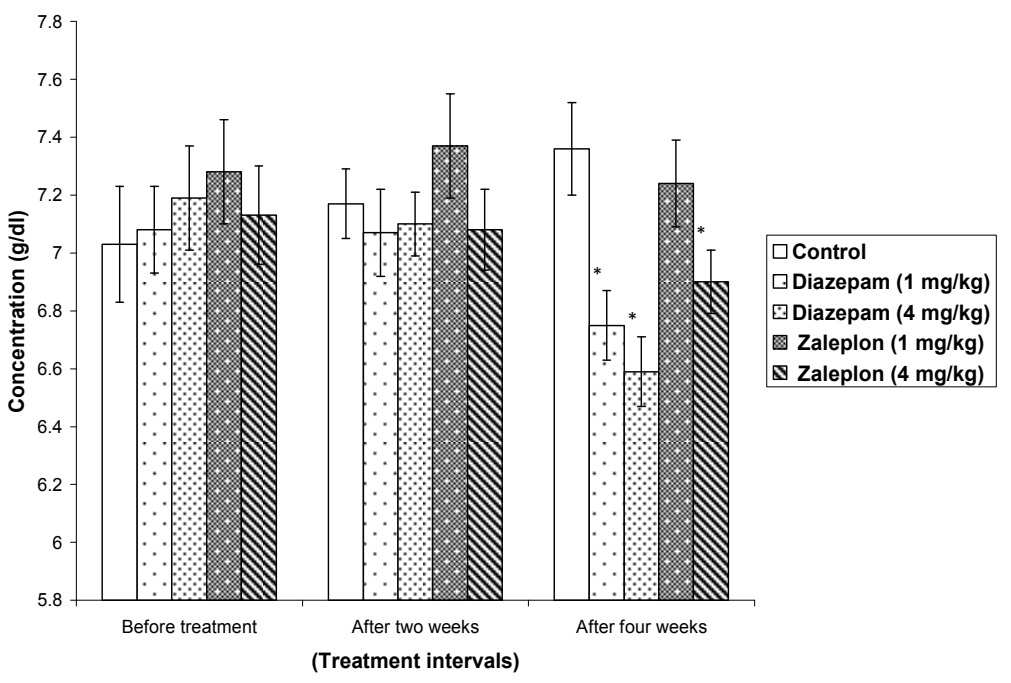

Figure 9. Effect of diazepam and zaleplon on rats' serum total protein.

* Significantly different from corresponding control group values at $(p<0.05)$.

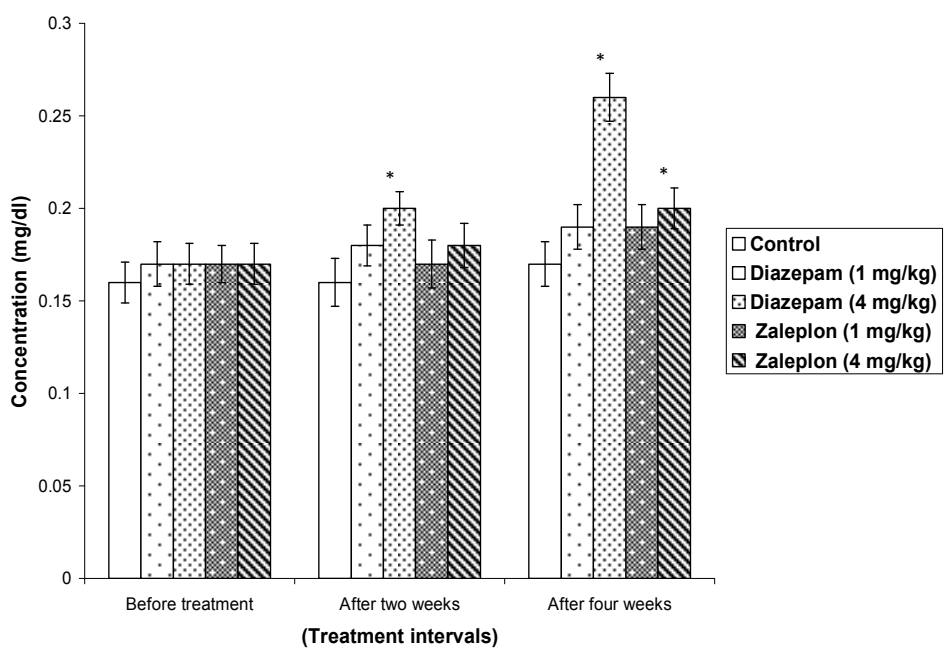

Figure 10. Effect of diazepam and zaleplon on rats' serum direct billirubin.

* Significantly different from corresponding control group values at $(p<0.05)$.

Effect of diazepam and zaleplon on rats' serum total billirubin

Diazepam (1 $\mathrm{mg} / \mathrm{kg}$, p.o.) and zaleplon (4 $\mathrm{mg} / \mathrm{kg}$, p.o.) induced significant increase on serum total billirubin by $13.9 \%$ and $20 \%$ respectively after four weeks. Also, diazepam (4 $\mathrm{mg} / \mathrm{kg}, \quad$ p.o.) led to significant increase on serum total billirubin by $11.1 \%$ after two weeks and $30.4 \%$ after four weeks in comparison with that of corresponding control group values as shown in Figure (11).

Effect of diazepam and zaleplon on rats' serum creatinine:

Diazepam (1 $\mathrm{mg} / \mathrm{kg}$, p.o.) and zaleplon (4 mg/kg, p.o.) showed significant increase on serum creatinine 
by $18.8 \%$ and $16.7 \%$ after four weeks respectively. As well as, diazepam (4 $\mathrm{mg} / \mathrm{kg}$, p.o.) led to significant increase on serum creatinine by $20.9 \%$ after two weeks and $25 \%$ after four weeks comparing to corresponding control group values as shown in Figure (12).

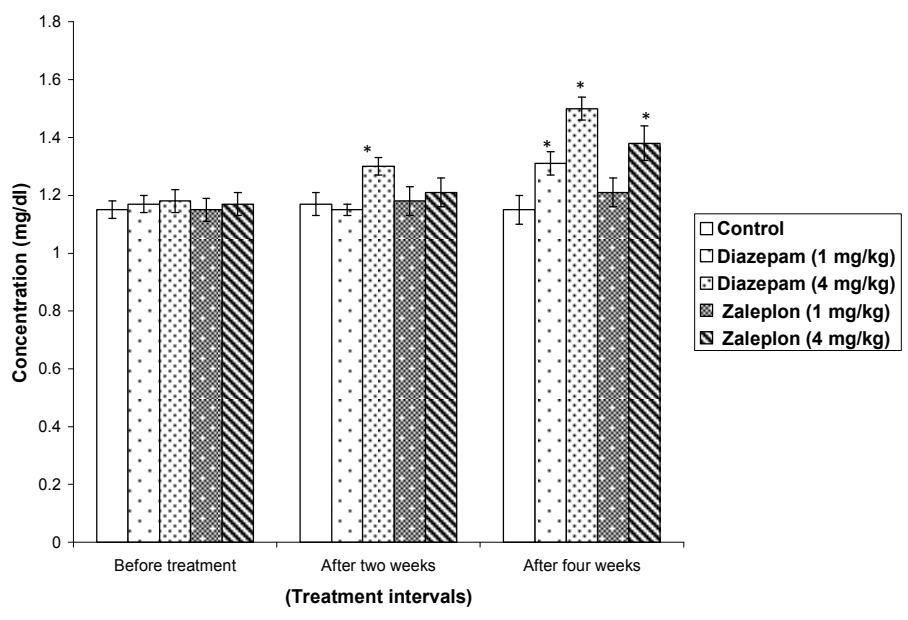

Figure 11. Effect of diazepam and zaleplon on rats' serum total billirubin.

* Significantly different from corresponding control group values at $(p<0.05)$.

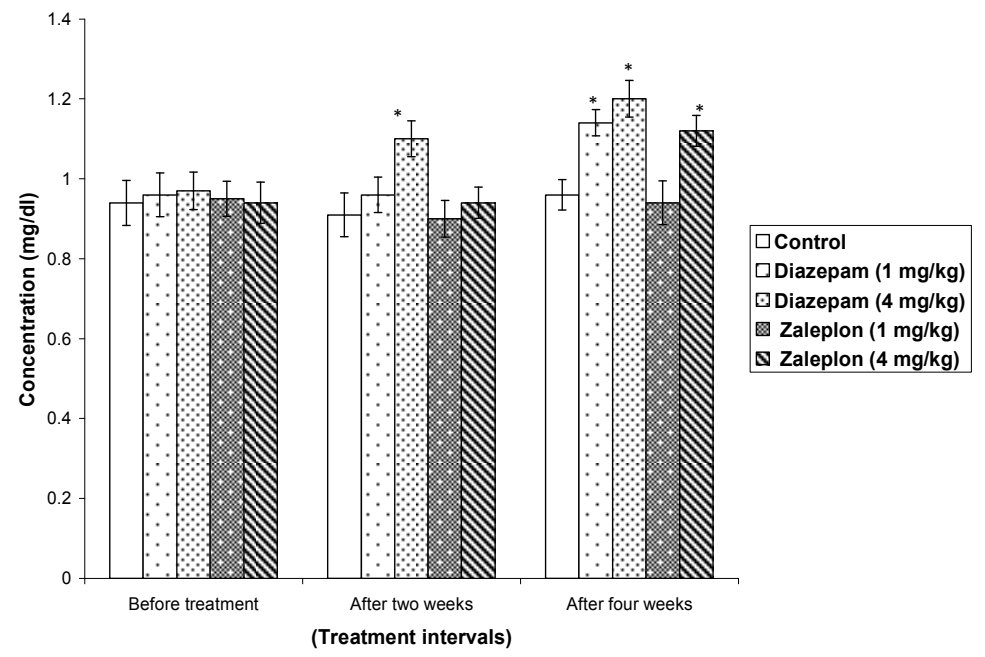

Figure 12. Effect of diazepam and zaleplon on rats' serum creatinine.

* Significantly different from corresponding control group values at $(p<0.05)$.

Effect of diazepam and zaleplon on rats' blood urea nitrogen:

Diazepam (4 $\mathrm{mg} / \mathrm{kg}$, p.o.) performed significant increase on blood urea nitrogen by $8 \%$ after four weeks as compared with corresponding control group values as shown in Figure (13). 


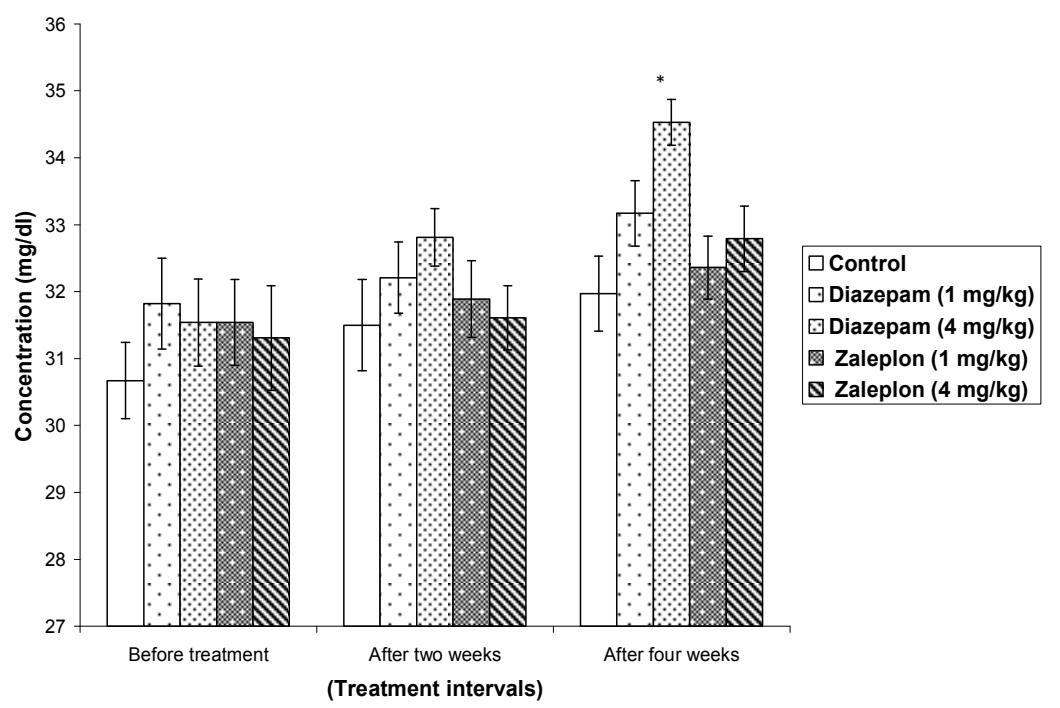

Figure 13. Effect of diazepam and zaleplon on rats' blood urea nitrogen.

* Significantly different from corresponding control group values at $(\mathrm{p}<0.05)$.

\section{DISCUSSION}

Anxiety disorders are frequently treated using benzodiazepine and nonbenzodiazepine anxiolytics (Morin et al., 2004; Dolder et al., 2007). Where, they should be prescribed for short periods only with the frequency and duration of use customized to each patient's circumstances (Ramakrishnan and Scheid, 2007).

For the motor co-ordination assay, the results of the current work for zaleplon (1 and $4 \mathrm{mg} / \mathrm{kg}$, p.o.) were supported by Sanger et al., (1996), who reported that; in general, zaleplon had no effect on rotarod performance when taken as recommended dose $(1 \mathrm{mg} / \mathrm{kg})$ for short term of administration (15 days). However, it obtained a decrease in rotarod performance (muscle incoordinaion) incase of high dose (3 $\mathrm{mg} / \mathrm{kg}$ ) for long term of administration (30 days). In addition, Foster et al., (2004) reported that; zaleplon affected on rotarod performance in a dosedependant manner. So, high dose of zaleplon administration (5 $\mathrm{mg} / \mathrm{kg})$ produced rotarod performance deficits, which attributed to muscle relaxation.

Also, the results of the present work for diazepam (1 \& $4 \mathrm{mg} / \mathrm{kg}$, p.o.) were in agreement with Sarris (2007); Bodkin et al., (2012), who reported that, diazepam had no effect on performance of rats on the rotarod for short term of administration. However, for long term of diazepam administration, there was a clear effect on performance of rats on the rotarod by decreasing the ability of rats to balance on the rotarod, deducing that: diazepam may exert its anxiolytic action by direct action on the central nervous system giving muscle relaxation and not through sedation.

For the anxiety performance assay, the results of the present study for zaleplon (1 and $4 \mathrm{mg} / \mathrm{kg}$, p.o.) were clarified by Foda and Bakhaidar (2010), who stated that, zaleplon produced hypnotic properties and decrease in anxiety performance due to binding selectively with high efficacy to the benzodiazepine site $\left(\mathrm{GO}_{1}\right)$ on the $\left(\alpha_{1}\right)$ containing $\mathrm{GABA}_{\mathrm{A}}$ receptors, which explained the decrease of anxiety 
performance in the present work. Moreover the current result was in line with Paparrigopoulos et al., (2008), who reported that; zaleplon induced anxiolytic, sedative-hypnotic, anticonvulsant and anti-conflict effects by a decrease in anxiety performance via its binding to the central nervous system (CNS)-type benzodiazepine receptors.

Also, the results of the present work for diazepam (1 \& $4 \mathrm{mg} / \mathrm{kg}$, p.o.) were explained by Mandrioli et al., (2010), who mentioned that; diazepam led to CNS depression and lowered the anxiety performance by potentiating the action of the inhibitory neurotransmitter (GABA) through binding directly to a site on GABA receptor that is distinct from the binding site of the endogenous GABA molecule, recognized as the $\alpha$ subunit of the $\mathrm{GABA}_{\mathrm{A}}$ receptor, leading to an alteration in the functional response when the receptor is activated by GABA. This binding leads to activation of GABA receptor, then increasing the frequency of chloride channel opening leading to more $\mathrm{Cl}^{-}$ions influx. In addition, Rex et al., (2002); Himmel (2008) reported that; diazepam resulted in CNS depression and decrease in anxiety performance, where it acts as a positive allosteric agonist of the postand pre-synaptic $\mathrm{GABA}_{\mathrm{A}}$ receptor chloride channel complex leading to potentiating the activity of brain's major inhibitory neurotransmitter (GABA) and lowering the activity of brain's major excitatory neurotransmitters (Glutamate and Aspartate) of rats.

As regard for the heart rate and blood pressure measurement, the results of the present work for zaleplon ( 1 and $4 \mathrm{mg} / \mathrm{kg}$, p.o.) were explained by Mandrioli et al., (2010), who reported that; zaleplon has no effect on blood pressure or heart rate at recommended doses (1 $\mathrm{mg} / \mathrm{kg}$ ). However at high doses (3 and $5 \mathrm{mg} / \mathrm{kg}$ ) especially with long term of administration (one month), it decreased significantly the heart rate and blood pressure, where the adverse effects associated with zaleplon seem to be more rapidly resolved and less severe than those associated with benzodiazepine and other non-benzodiazepine hypnotics with a longer duration of action. Also, Weitzel et al., (2000) reported that; zaleplon decreased heart rate and blood pressure at high dose only (4 $\mathrm{mg} / \mathrm{kg}$ ) with a lesser extent than benzodiazepine hypnotics. But at therapeutic dose $(1 \mathrm{mg} / \mathrm{kg})$, there is no effect on heart rate or blood pressure. Moreover, Sanchez et al., (2000) stated that; zaleplon has no effect on blood pressure or heart rate, when administered at recommended dose $(1 \mathrm{mg} / \mathrm{kg})$ either alone or in combination with digoxin.

Also, the results of the current study for diazepam $(1 \& 4 \mathrm{mg} / \mathrm{kg}$, p.o. $)$ were in line with Kitajima et al., (2004); Grossman et al., (2005); Zahner et al., (2007), who reported that; systolic and mean blood pressure and heart rate decreased significantly after diazepam administration $(1 \mathrm{mg} / \mathrm{kg})$ attributing to central action of diazepam not peripheral one. Where, the nucleus of the solitary tract in the medulla plays an important role in controlling blood pressure and contains GABA receptors. Also, hypothalamus plays an important role in controlling blood pressure. As, diazepam acted directly on GABA receptors in medulla as an agonist and on hypothalamus.

As regard for brain neurotransmitters (Free amino acids and 
monoamines) assay, the results of the present work for zaleplon (1 and 4 $\mathrm{mg} / \mathrm{kg}$, p.o.) were in agreement with Foda and Bakhaidar (2010); Mandrioli et al., (2010) who mentioned that; zaleplon led to CNS depression and produced its therapeutic hypnotic properties especially at high dose $(5 \mathrm{mg} / \mathrm{kg})$, where it selectively binds with high efficacy to the benzodiazepine site $\left(\mathrm{G}_{1}\right)$ on the $\left(\alpha_{1}\right)$ containing $\mathrm{GABA}_{\mathrm{A}}$ receptors. This binding leads to activation of GABA receptor, then increasing the frequency of chloride channel opening leading to more $\mathrm{Cl}^{-}$ions influx. Also, Sullivan et al., (2004); Monti (2011) reported that; non-benzodiazepine drugs (eg. Zaleplon) had no effect on most of brain neurotransmitters except for GABA and serotonin, which increased significantly by using non-benzodiazepine drugs exerting their sedative and hypnotic action.

Also, the results of the present work for diazepam (1\&4 mg/kg, p.o.) were explained by Riss et al., (2008); Mandrioli et al., (2010), who mentioned that; diazepam elevated GABA level by potentiating the action of the inhibitory neurotransmitter (GABA) through binding directly to a site on GABA receptor that is distinct from the binding site of the endogenous GABA molecule, recognized as the $\alpha$-subunit of the $\mathrm{GABA}_{\mathrm{A}}$ receptor. Moreover, Rex et al., (2002); Himmel (2008) reported that; diazepam resulted in CNS depression, where it acts as a positive allosteric agonistic of the post- and pre-synaptic $\mathrm{GABA}_{\mathrm{A}}$ receptor - chloride channel complex leading to potentiating the activity of brain's major inhibitory neurotransmitter (GABA) and lowering the activity of brain's major excitatory neurotransmitters (glutamate and aspartate). Which explain our present result for GABA, glutamate and aspartate. Furthermore, the increase in brain dopamine and serotonin levels in current result is clarified by Straub et al., (2010) who reported that, diazepam elevated dopamine and serotonin content in the brain of mice due to its dopaminergic and serotonergic activity. Oppositely, it lowered nor-epinephrine content in the brain of mice resulting in calming down and anxiolytic effect.

As regard for the hepatotoxiciy assay, the results of the present work for zaleplon (1 and $4 \mathrm{mg} / \mathrm{kg}$, p.o.) were in line with Curran and Musa (2001); Clint et al., (2008), who mentioned that; zaleplon is the most widely anxiolytic drug used due to its high safety margin, but its long term use (40 days) for treatment of anxiety and insomnia produced mild hepatotoxicity, where liver enzymes (ALT \& AST) activity, serum billirubin (total \& direct) and alkaline phosphatase activity were elevated and serum protein (eg. albumin) was decreased. Moreover the current work was in agreement with Moore et al., (2003); Zientek et al., (2010), who reported that; zaleplon induced mild hepatotoxicity, so it was taken with caution for hepatic patients, where prolonged use of zaleplon (30 days) causes impairment of rat liver function, generation of free radicals in different regions of rat brain alleviating lipid peroxidation in various tissues, where lipid peroxidation plays an important role in hepatotoxicity of zaleplon.

Also, the results of the present work for diazepam $(1 \& 4 \mathrm{mg} / \mathrm{kg}$, p.o.) were in agreement with Musavi and Kakkar (2003); Nandhini and Anuradha (2003), who reported that; long term use (30 days) of diazepam for treatment of anxiety and insomnia produced hepatotoxicity, whereas it attributed to 
elevation in liver enzymes (ALT \& AST) activity, serum billirubin (total \& direct), alkaline phosphatase activity and malondialdehyde formation and decrease in reduced glutathione content and serum protein (eg. albumin). Also the current result was in compatibility with Seckin et al., (2007), who mentioned that; prolonged use of diazepam causes hepatotoxicity by impairment of rat liver function, generation of free radicals in different regions of rat brain alleviating lipid peroxidation in various tissues and inhibiting the activity of $\mathrm{Ca}^{+2}-$ ATPase leading to the calcium accumulation, where calcium accumulation together with increased lipid peroxidation may play an important role in diazepam induced hepatotoxicity. Furthermore, Chatterjee et al., (2009) reported that; diazepam treatment induced hepatotoxicity due to increase significantly in diene conjugate formation levels with parallel marked increase in malondialdehyde formation levels and decrease in reduced glutathione content. The above explanations supported current work for diazepam induced hepatotoxicity.

As regard for the nephrotoxicity assay, the results of the present work for zaleplon ( 1 and $4 \mathrm{mg} / \mathrm{kg}$, p.o.) were in line with Moore et al., (2003), who reported that; zaleplon is used widely as an anxiolytic drug due to its high safety margin on vital organs, but its long term use (6 weeks) especially with high dose $(4 \mathrm{mg} / \mathrm{kg}$ ) for treatment of anxiety and insomnia induced mild nephrotoxicity, where serum creatinine and urea nitrogen were elevated but urea nitrogen elevation was with a lesser extent than serum creatinine elevation. Also, Petroski et al., (2006) mentioned that: zaleplon was taken safely for renal impairment patients, where prolonged use (30 days) of zaleplon at recommended dose $(1 \mathrm{mg} / \mathrm{kg})$ did not induce any alteration in kidney functions. However, prolonged use (30 days) of zaleplon at high dose $(4 \mathrm{mg} / \mathrm{kg})$ induced slight changes in kidney functions, as an increase in serum creatinine level.

As well as, the results of the present work for diazepam (1 \& 4 $\mathrm{mg} / \mathrm{kg}$, p.o.) were in compatibility with Kim et al., (2010), who reported that; diazepam was considered as the most widely anxiolytic drug used from several decades. But, it has been found that; diazepam affects kidney functions leading to kidney impairment or nephrotoxicity, which mainly by elevating serum creatinine and blood urea nitrogen. Consequently, diazepam must be taken with great caution for renal patients especially incase of long term of administration (30 days). Also these results were in agreement with Mandrioli et al., (2010), who reported that; long term use (45 days) of benzodizepines (eg. diazepam) for treatment of anxiety and insomnia produced nephrotoxicity, which is attributed to elevation in serum creatinine and blood urea nitrogen, in contrast, reduction in urine output volume.

In conclusion: benzodiazepine anxiolytics (ex. Diazepam) should be used for short periods avoiding their adverse effects of long periods. Nonbenzodiazepine anxiolytics (ex. Zaleplon) can be used for long periods instead of benzodiazepine anxiolytics (ex. Diazepam) due to their great safety margin. Overdoses of benzodiazepine and non-benzodiazepine anxiolytics produce great side effects, however zaleplon is with a lesser extent. So, 
zaleplon is safer than diazepam in treatment of anxiety.

\section{REFERENCES}

1. Becker, P. M. (2006). Treatment of sleep dysfunction and psychiatric disorders. Curr Treat Options Neurol 8 (5): $367-375$.

2. Bodkin, R.; Schneider, S.; Rekkerth, D.; Spillane, L. and Kamali, M. (2012). Rhabdomyolysis associated with kava ingestion. Am $J$ Emerg Med 30 (4): 635.

3. Braun, A. A.; Skelton, M. R.; Vorhees, C. V. and Williams, M. T. (2011). Comparison of the elevated plus and elevated zero mazes in treated and untreated male SpragueDawley rats: Effects of anxiolytic and anxiogenic agents. Pharmacol Biochem Behav 97: 406 - 415.

4. Carlson, N. R. and Donald, C. H. (2010). Psychology the science of behaviour., Toronto, Ontario: Pearson Canada Inc. pp. 558.

5. Chatterjee, S.; Chatterjee, J.; Chaudhur, K.; Basu, S. and Maitti, C. (2009). Hepatotoxicity of diazepam: Structural and trace metal studies in rat. Biol Trace Elem Res 57: $239-249$.

6. Clint, J. L.; Bernabe, F.; Carlos, B.; Miguel, A. P.; Anabel, B. and Yolanda, E. (2008). A case of zaleplon overdose. Clin Toxicol 46: 782.

7. Cocchetto, D. M. and Bjornsson, T. D. (1983). Methods for vascular access and collection of body fluids from the laboratory rat. $J$ Pharm Sci 72 (5): $465-92$.

8. Curran, K. P. and Chalasani, S. H. (2012). Serotonin circuits and anxiety: what can invertebrates teach us? Invert Neurosci 12: 81 - 92.
9. Curran, S. and Musa, S. (2001). Hypnosedatives and anxiolytics. Side Effects of Drugs Annual 24: 45 - 52.

10. Davison and Gerald, C. (2008). Abnormal Psychology. Toronto: Veronica visentin. pp. 154.

11. Degiorgio, E. R. (1974). Effective valve for inflating an endotracheal tube cuff. Anesthesiology 26: 227.

12. Dolder, C., Nelson, M. and Mckinsey, J. (2007): Use of nonbenzodiazepine hypnotics in the elderly: are all agents the same? $C N S$ drugs; 21 (5): 389 - 405.

13. Doyle, A. C. and Pollack, M. H. (2003). Establishment of remission criteria for anxiety disorders. $J$ Clin Psychiatry 64: 40 - 45.

14. Foda, N. H. and Bakhaidar, R. B. (2010). Zaleplon. Profiles Drug Subst Excip Relat Methodol 35: 347 -372 .

15. Follesa, P., Mancuso, L., Biggio, F., Cagetti, E., Franco, M., Trapani, G. and Biggio, G. (2002): Changes in GABA (A) receptor gene expression induced by withdrawal of, but not by long-term exposure to zaleplon or zolpidem. Neuropharmacol 42 (2): $191-198$.

16. Foster, A. C.; Pelleymounter, M. A.; Cullen, M. J.; Lewis, D.; Joppa, M.; Chen, T. K.; Bozigian, H. P.; Gross, R. S. and Gogas, K. R. (2004). In Vivo Pharmacological Characterization of Indiplon, a Novel Pyrazolopyrimidine Sedative Hypnotic. J Pharmacol Exp Ther 311 (2): 547 - 559.

17. Ganzberg, S. I.; Dietrich, T.; Valerin, M. and Beck, F. M. (2005). Zaleplon $\left(\right.$ Sonata ${ }^{\circledR}$ ); oral sedation for outpatient: third molar extraction surgery. Anesth Prog 52 (4): 128 131. 
18. Grossman, E.; Nadler, M.; Sharabi, Y.; Thaler, M.; Shachar, A. and Shamiss, A. (2005). Anti-anxiety treatment in patients with excessive hypertension. Am J Hypertens 18 (9): $1174-1177$.

19. Heinrikson, R. L. and Meredith, S. C. (1984). Amino acid analysis by RP-HPLC: precolumn derivatization with phenylisothiocyanate. Anal Biochem 136: 65 - 74.

20. Henig, R. (2009). Anxiety. The New York Times Magazine 1.

21. Henry, P. D.; Sobel, B. E. and Braunwald, E. (1974). Protection of hypoxic guinea pig hearts with glucose and insulin. The American $J$ Physiol 226 (2): 309 - 313.

22. Himmel, H. M. (2008). Safety pharmacology assessment of central nervous system function in juvenile and adult rats: effects of pharmacological reference compounds. J Pharmacol Toxicol Methods 58 (2): 129 - 146.

23. Irvine, R. J.; White, J. and Chan, R. (1997). The Influence of restraint on blood pressure in the rat. $J$ Pharmacol Toxicol Methods 38: 157 $-162$.

24. Kauppila, T.; Tanila, H.; Carlson, S. and Taira, T. (1991). Effects of atipamezole, a novel alpha 2adrenoceptor antagonist, in openfield, plus-maze, two compartment exploratory and forced swimming tests in the rat. Eur J Pharmacol 205 (2): $177-82$.

25. Kim, H. S.; Sakai, N.; Saito, K.; Fujita, S. and Ishizuka, M. (2010). Diazepam metabolism in the kidneys of male and female rats of various strains. J Vet Med Sci 72 (1): 7 - 11.

26. Kitajimaa, T.; Kanbayashib, T.; Saitob, Y.; Takahashib, Y.; Ogawab, Y.; Sugiyamab, T.; Kanekob, Y.;
Aizawab, R. and Shimizub, T. (2004). Diazepam reduces both arterial blood pressure and muscle sympathetic nerve activity in human. Neurosci Lett 355: 77 - 80.

27. Lundblad, C.; Bentzer, P. and Grände, PO. (2003). Inhibition of Rho kinase decreases hydraulic and protein microvascular permeability in cat skeletal muscle. Microvasc Res 66 (2): $126-33$.

28. Mandrioli, R.; Mercolini, L. and Raggi, MA. (2010). Metabolism of benzodiazepine and nonbenzodiazepine anxiolytic-hypnotic drugs: an analytical point of view. Curr Drug Metab 11: 815 - 829.

29. Monti, J. M. (2011). Serotonin control of sleep-wake behavior. Sleep Med Rev 15: 269 - 281.

30. Moore, K. A.; Zemrus, T. L.; Ramcharitar, V.; Levine, B. and Fowler, DR. (2003). Mixed drug intoxication involving zaleplon ("Sonata"). Forensic Sci Int 134 (2 3): $120-122$.

31. Morin, C. M., Belanger, L. and Bernier, F. (2004): Correlates of benzodiazepine use in individuals with insomnia. Sleep Med 5 (5): 457 -462 .

32. Musavi, S. and Kakkar, P. (2003). Effect of diazepam treatment and its withdrawal on pro/antioxidative processes in rat brain. Mol Cell Biochem 245: 51 - 56.

33. Naghibi, B. and Rayatnia, F. (2011). Co-administration of sub-effective anxiolytic doses of diazepam and hydroxyzine in elevated zero-maze in mice. Psychiatry Investig 8 (2): $169-173$.

34. Nandhini, T. A. and Anuradha, C. V. (2003). Inhibition of lipid peroxidation protein glycation and elevation of membrane ion pump 
activity by taurine in red blood cells exposed to high glucose. Clin Chem Acta 336: 129 - 135.

35. Noguchi, H., Kitazumi, K., Mori, M. and Shiba, T. (2002): Effect of Zaleplon on learning and memory in rats. Naunyn-Schmiedebergs Arch Pharmacol 366 (2): 183 - 188.

36. Pagel, P.; Blome, J. and Wolf, HU. (2000). High performance liquid chromatographic separation and measurements of various biogenic compounds possibly involved in the pathomechanism of Parkinson's disease. J Chromatogtr B Biomed Sci Appl 746: 297 - 304.

37. Pandi-Perumal, S. R., Verster, J. C., Kayumov, L., Lowe, A. D., Santana, M. G., Pires, M. L., Tufik, S. and Mello, M. T. (2006): Sleep disorders, sleepiness and traffic safety: a public health menace. Braz J Med Biol Res 39 (7): $863-871$.

38. Paparrigopoulos, T.; Tzavellas, E.; Karaiskos, D. and Liappas, I. (2008). Intranasal zaleplon abuse. $A m \quad J$ Psychiatry 165 (11): 1489 - 1490.

39. Petroski, R. E.; Pomeroy, J. E.; Das, R.; Bowman, H.; Yang, W.; Chen, A. P. and Foster, A. C. (2006). Indiplon is a high affinity positive allosteric modulator with selectivity for alpha1 subunit containing GABA $_{\mathrm{A}}$ receptors. J Pharmacol Exp Ther 317 (1): 369 - 77.

40. Pigott, T. A. (2003). Anxiety disorders in women. Psychiatr Clin North Am 26: 621 - 672.

41. Ramakrishnan, K. and Scheid, D. C. (2007). Treatment options for insomnia. Am Fam Physician 76 (4): $517-526$.

42. Reitman, S. and Frankel, S. (1957). A colorimetric method for the determination of serum glutamic oxalacetic and glutamic pyruvic transaminases. Am J Clin Pathol 28 (1): $56-63$.

43. Rex, A.; Morgenstern, E. and Fink, H. (2002). Anxiolytic-like effects of Kava-Kava in the elevated plus maze test-a comparison with diazepam. Prog Neuropsychopharmacol Biol Psychiatry 26: 855 - 860 .

44. Riss, J.; Cloyd, J.; Gates, J. and Collins, S. (2008). Benzodiazepines in epilepsy: pharmacology and pharmacokinetics. Acta Neurol Scand 118 (2): 69 - 86.

45. Salum, C.; Roque-da-Silva, A. C. and Morato, S. (2003). Conflict as a determinant of rat behavior in three types of elevated plus-maze. Behav Processes 63 (2): 87 - 93.

46. Sanchez, G. P.; Paty, I.; Leister, C. A.; Guerra, P.; Frías, J.; García Pérez, L. E. and Darwish, M. (2000). Effect of zaleplon on digoxin pharmacokinetics and pharmacodynamics. Am J Health Syst Pharm 57 (24): 2267 - 2270.

47. Sanger, D. J.; Morel, E. and Perrault, G. (1996). Comparison of the pharmacological profiles of the hypnotic drugs, zaleplon and zolpidem. Eur J Pharmacol 313: 35 -42 .

48. Sarris, J. (2007). Herbal medicines in the treatment of psychiatric disorders: A systematic review. Phytother Res 21: $703-716$.

49. Seckin, S.; Alsancak, S.; Kucukgergin, C. B. and Uysal, M. (2007). The effect of chronic diazepam administration on lipid peroxidation and $\mathrm{Ca}^{+2}-$ ATPase activity in rat liver. Acta Biol Hung 58 (4): $441-443$.

50. Straub, C. J.; Carlezon, W. A. and Rudolph, U. (2010). Diazepam and cocaine potentiate brain stimulation 
reward in $\mathrm{C} 57 \mathrm{BL} / 6 \mathrm{~J}$ mice. Behav Brain Res 206: 17 - 20.

51. Sullivan, S. K.; Petroski, R. E.; Verge, G.; Gross, R. S.; Foster, A. C. and Grigoriadis, DE. (2004). Characterization of the interaction of indiplon, a novel pyrazolopyrimidine sedative-hypnotic, with the $\mathrm{GABA}_{\mathrm{A}}$ receptor. J Pharmacol Exp Ther 311 (2): $537-546$.

52. Sylvers, P.; Lilienfeld, S. O. and LaPrairie, J. L. (2011). Differences between trait fear and trait anxiety: implications for psychopathology. Clin Psychol Rev 31 (1): 122 - 137.

53. Tabacco, A.; Meiattini, F.; Moda, E. and Tarli, P. (1979). Simplified enzymatic/colorimetric serum urea nitrogen determination. Clin Chem 25 (2): 336 - 337.

54. Walter, P. and Stucki, J. W. (1970). Regulation of pyruvate metabolism in rat liver mitochondria. Hoppe Seylers Z Physiol Chem 72 (4): 471 474.

55. Weitzel, K. W.; Wickman, J. M.; Augustin, S. G. and Strom, J. G. (2000). Zaleplon: a pyrazolopyrimidine sedativehypnotic agent for the treatment of insomnia. Clin Ther 22 (11): 1254 1267.

56. Zahner, M. R.; Pei Li, D. and Lin Pan, H. (2007). Benzodiazepine inhibits hypothalamic presympathetic neurons by potentiating of GABAergic synaptic input. Neuropharmacol 52: 467 - 475.

57. Zientek, M.; Jiang, Y.; Youdim, K. and Obach, R. S. (2010). In vitro and in vivo correlation for intrinsic clearance for drugs metabolized by human aldehyde oxidase. Drug Metab Dispos 38 (8): 1322 - 1327. 
Vol. 23, Issue. 1, pp, 1-15

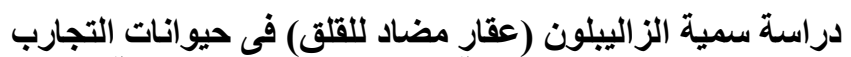

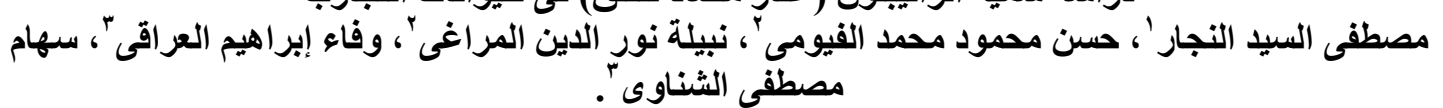

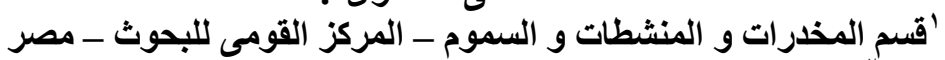

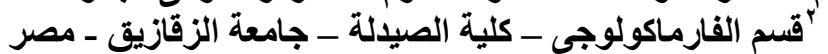

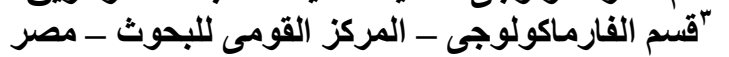

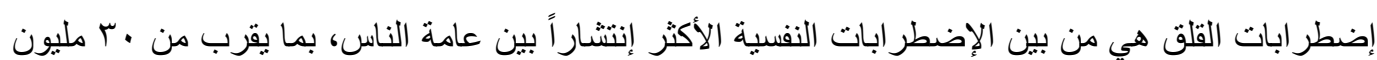

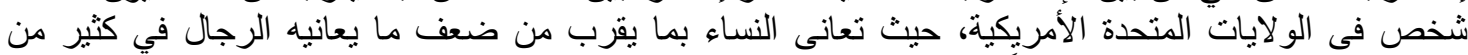

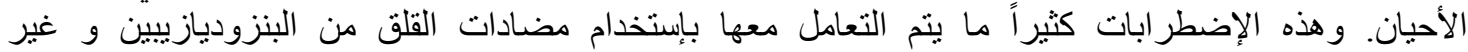

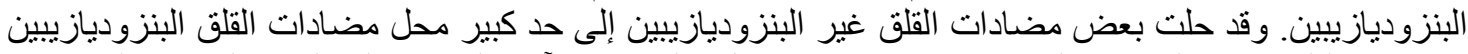

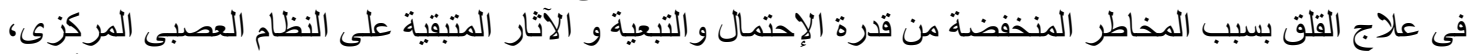

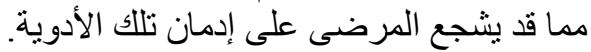

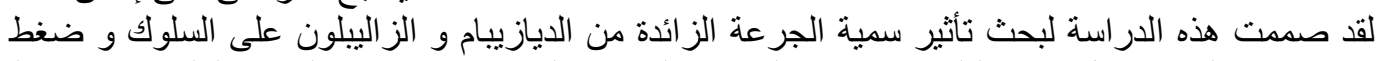

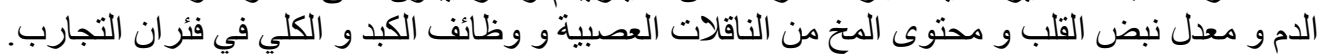

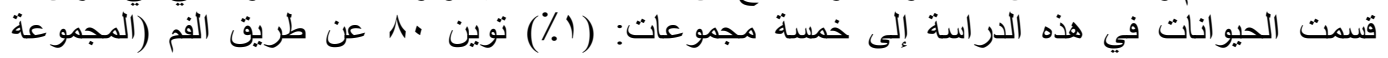

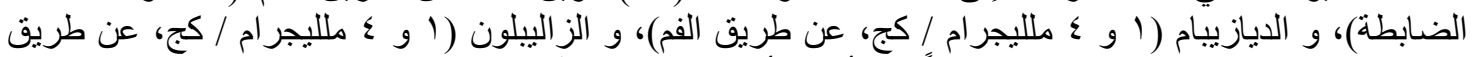

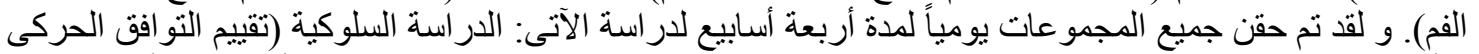

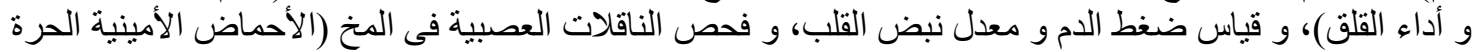

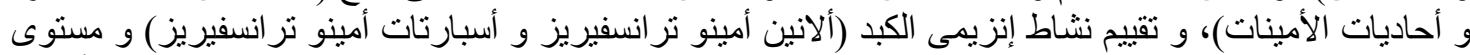

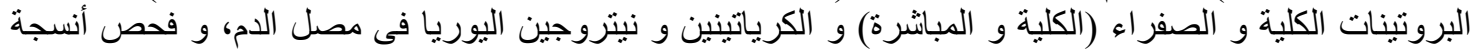
الكبد و الكلى لفئران التجارب.

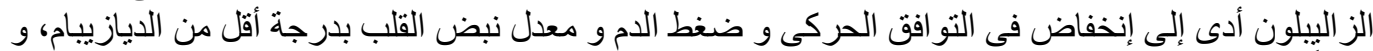

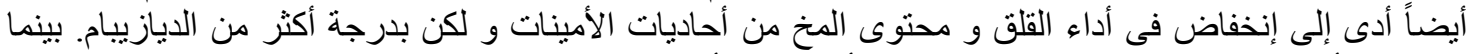

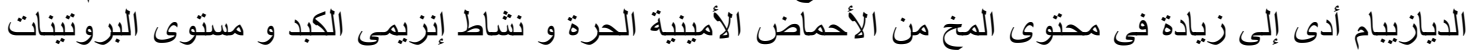

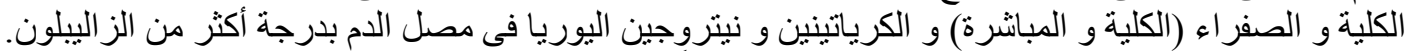

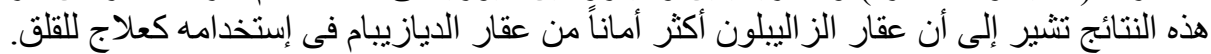

